\title{
Development of esophageal adenocarcinoma on buried glands following radiofrequency ablation for Barrett's esophagus
}

Radiofrequency ablation (RFA) of Barrett's esophagus mucosa is associated with high rates of complete eradication of intestinal metaplasia and dysplasia [1]. RFA can be combined with endoscopic mucosal resection (EMR) when superficial adenocarcinoma is present. After RFA the likelihood of buried glands under the layer of neosquamous epithelium is lower than after photodynamic therapy or argon plasma coagulation [2].

We report the first case of buried Barrett's adenocarcinoma developing after RFA. A 55-year-old man with a history of alcoholic cirrhosis was admitted for treatment of a C0M3 Barrett's esophagus with a superficial adenocarcinoma resected by EMR. The resection was complete and complementary RFA was performed to eradicate the remaining Barrett's esophagus mucosa with high grade dysplasia. Endoscopic follow-up after two sessions of RFA (with a $360^{\circ}$ and $90^{\circ}$ probe, respectively) revealed a $10-\mathrm{mm}$ islet of Barrett's esophagus without dysplasia. Another endoscopic followup 10 months later showed a 7-mm, elevated nodule in the squamous epithelium of the lower esophagus, which was classified as T1NOM0 with endoscopic ultrasonography and removed by EMR. Histological analysis revealed invasive adenocarcinoma developing under the normal squamous epithelium ( Fig. 1 ). The resection was $\mathrm{R} 1$ and because of the underlying liver cirrhosis, external radiation therapy was proposed.

- Fig. 1 clearly demonstrates that the adenocarcinoma developed in the glands located beneath the squamous epithelium. Recurrence of the previously resected adenocarcinoma was unlikely since the

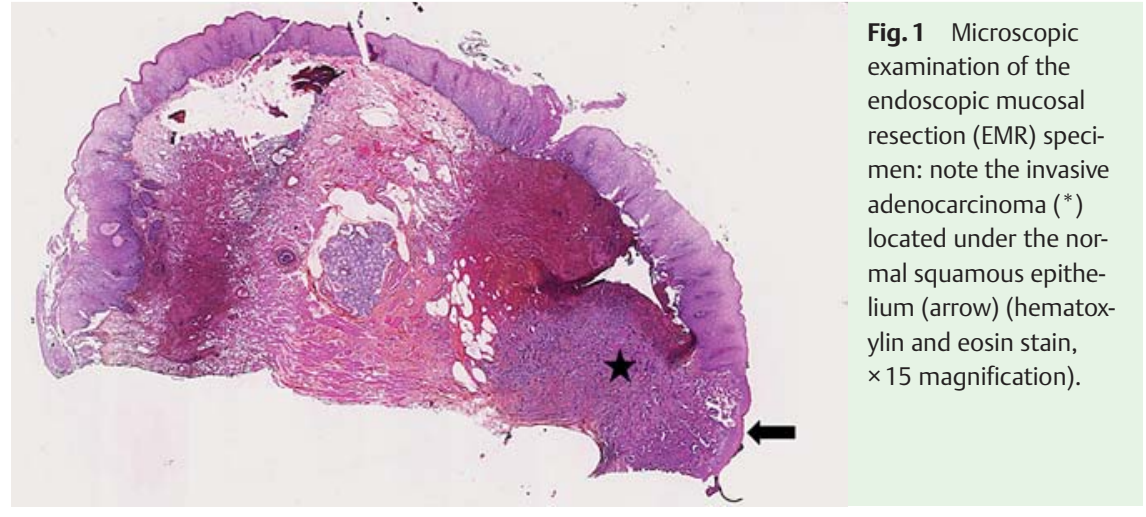

resection was complete. Considering the short time interval between the RFA and the discovery of the adenocarcinoma, the second neoplasm more likely originated in the buried dysplastic glands. In conclusion, clinicians must be aware of the possibility after RFA of the development of new adenocarcinoma in dysplastic or nondysplastic glands buried under the neosquamous epithelium. The present case report further justifies the need for close endoscopic surveillance after RFA.

Endoscopy_UCTN_Code_CCL_1AB_2AC_3AC

Competing interests: None

\section{E. Chabrun ${ }^{1}$, M. Marty ${ }^{2}$, F. Zerbib ${ }^{1}$}

${ }^{1}$ Gastroenterology Department, Saint André Hospital, and Université Victor Segalen Bordeaux 2, Bordeaux, France

2 Pathology Department, Haut Lévêque Hospital, Bordeaux, France

\section{References}

1 Shaheen NJ, Sharma P, Overholt BF et al. Radiofrequency ablation in Barrett's esophagus with dysplasia. N Engl J Med 2009; 360: $2277-2288$

2 Gray NA, Odze RD, Spechler SJ. Buried Metaplasia after endoscopic ablation of Barrett's esophagus: a systematic review. Am J Gastroenterol 2011; 106: 1899-1908

\section{Bibliography}

DOI http://dx.doi.org/ 10.1055/s-0032-1310245

Endoscopy 2012; 44: E392

(c) Georg Thieme Verlag KC

Stuttgart · New York

ISSN 0013-726X

\section{Corresponding author}

Professor F. Zerbib

Gastroenterology Department

Saint André Hospital

1, rue Jean Burguet

33075 Bordeaux

France

Fax: + 33-556-794781

frank.zerbib@chu-bordeaux.fr 